\title{
Assessment of Excess Gamma Dose Exposure Level in Typical Nigeria Commercial Building Materials Distribution Outlets
}

\author{
A. M. Asere ${ }^{\mathrm{a}, *}$, T. O. Owolabi ${ }^{\mathrm{a}}$, B. D. Alafe ${ }^{\mathrm{a}}$, O. P. Alabi ${ }^{\mathrm{a}}$, M. B. Alimi ${ }^{\mathrm{a}}$ \\ ${ }^{a}$ Department of Physics and Electronics, Adekunle Ajasin University, Akungba Akoko, Ondo State, Nigeria
}

\begin{abstract}
The gamma dose rate exposure levels from different brands of building materials at commercial distribution stores/shops in two major cities in Ondo State, Nigeria, were measured using a well calibrated Inspector 1000 scintillator detector. The results showed that the different brands of building materials which are "Corrugated iron sheet, Aluminum roofing sheets, Conduit pipes, Paints, Cement, PVC pipes, Wash hand basin, Bath tub, Water closet, Kitchen zinc, Asbestos, Floor tiles, Wall tiles, Bullet proof door, Binding wire, rings and rods, Red bricks, Galvanized pipes, Copper pipes, Water tanks" contributed excess annual effective doses of $0.332 \mathrm{mSv} / \mathrm{y}$ and $0.311 \mathrm{mSv} / \mathrm{y}$ to store keepers in Ikare Akoko and Akure cities respectively. The indoor and outdoor annual effective dose of each of the investigated two cities are correlated using simple linear regression equations. The results of the modeling and experiment show that annual effective dose received by the occupants of these shops/stores was about $12 \%$ higher than what could be received in a typical natural radiation environment in the two cities because the building materials acts as a source of radiation indoor. The research indicated that the typical habit of using poorly ventilated and confined space as stores/shops by the sales men might subject them to internal exposure through inhalation of radon gas and its short-lived decay products. Implementation of the developed equations would definitely promote rapid determination of outdoor annual effective dose through indoor annual effective dose and ultimately save time and other valuable resources.
\end{abstract}

DOI: $10.46481 /$ jnsps.2021.188

Keywords: Building material, Ikare Akoko, Akure, indoor and outdoor gamma exposure, building material shop/store, annual effective dose.

Article History:

Received: 31 March 2021

Received in revised form: 28 June 2021

Accepted for publication: 30 June 2021

Published: 29 August 2021

(c)2021 Journal of the Nigerian Society of Physical Sciences. All rights reserved. Communicated by: W. A. Yahya

\section{Introduction}

Building materials are any materials which are used for construction purposes, such as materials for dwellings, offices and industrial premises. All building materials that are derived from soils and rocks always contain trace amount of natural radionuclides from potassium, uranium, and thorium series, and the radionuclides that are created as their radioactive decay chains $[1,2,3]$. Building materials may contain elevated concentration

${ }^{*}$ Corresponding author tel. no: $+234(0) 8067226208$

Email address: (A. M. Asere ) of any of the primordial radionuclides or radioactive elements as they occur in nature. Elevated concentrations of Natural Occurring Radioactive Materials (NORM) are often found in certain geological resources $[4,5]$. Human activities such as that of the building materials manufacturers, exploit these resources and may lead to significantly enhanced concentrations of radionuclides which may also enhance the potential for exposure to natural occurring radioactive materials in these products [6].

Human exposure to natural radiation from building materials is both internal and external. The external exposure is 
caused by gamma radiation that is released from the building material as a consequence of the radioactive decay of the natural radionuclides present in them while the internal exposure is mainly caused by alpha-particle due to inhalation of radon daughters from the decay of radium-226 which is released from building materials to indoor air $[7,8]$. Long time exposure to nuclear particles emissions from building materials may lead to several health issues [9]. The type of building material and where it is sourced from can determine the amount of radionuclides in the material since building materials reflect their geologic formation and origin $[10,11]$. Background radiation is a measure of the ionizing radiation present in the environment at a particular location which is not due to deliberate introduction of radiation sources. Background radiation originates from a variety of sources, both natural and artificial. These include both cosmic radiation and environmental radioactivity from naturally occurring radioactive materials as well as manmade fallout from nuclear weapons testing and nuclear accidents [12].

Some past researches have reported measurements of gamma dose exposure levels in various building materials in Nigeria $[13,14,15,16]$. Their studies indicated the particular brand of building materials that will present elevated levels of gamma dose exposure. [14] suggested that the controls of radioactivity of building materials could be based on a lower dose criteria in the range of $0.3-1.0 \mathrm{mSv} / \mathrm{y}$, if it is judged that this is desirable and will not lead to impractical control. This research further stated that the dose criteria used for the control of radioactivity should be defined as the excess exposure caused by the building materials. Thus, this study determined the gamma dose exposure from different brands of typical building materials commonly found and being used in Nigeria. Using the commercial stores/shops outlets in Ondo State, Southwestern Nigeria as a study area, the research was geared toward determining the extent at which the gamma dose exposure level inside the commercial building materials stores were in excess to gamma dose exposure in the local background environment.

The major practice of the owners of these shops outlets is to display samples of their goods outside the shops for advertisement and for customers to see while the bulk of their goods are inside the shop or another warehouse. The shop owners and sale representatives either sit outside or inside the shops or warehouse to attend to customers all day long. Most of these shops have one very small window or no window at all. These confined and poorly ventilated business workplaces expose all the small, medium and large scale business entrepreneurs to the effect of the radioactive emissions from the building materials. With $80 \%$ of their time spent indoor and $20 \%$ spent outdoor on daily basis, the occupants of these shop outlets may be receiving significant gamma dose from both the indoor and outdoor exposure unaware and without taken preventive measures.

\section{Study Area}

Two major cities in Ondo State, Southwestern Nigeria were used for the research study. The two cities are Akure and Ikare Akoko. Akure city is the state capital of Ondo State, Nigeria. It lies on latitude $7^{\circ} 25^{\prime}$ North of the equator and longitude $5^{\circ} 19^{\prime}$ East of the Greenwich Meridian. It stands on the altitude of about 370 meters above sea level. The climate is hot and humid, influenced by rain bearing monsoon winds from the ocean and dry Northwest wind from the Sahara desert. The rainy season varies from April to October with rainfall of about $1524 \mathrm{~mm}$ per year. The temperature varies from $28^{\circ} \mathrm{C}$ to $31^{\circ} \mathrm{C}$ with a mean annual relative humidity of about $80 \%$. Akure is a fast growing city and has its population increased tremendously over the years due to many factors. The city is the largest commercial center in Ondo State with several markets, industries and higher institutions. The research was carried out in major areas where building materials were being sold in large quantities, such as Arakale road, Nepa road, Oja Oba market and several other shops outlets for building materials.

Ikare Akoko city is about $100 \mathrm{~km}$ from Akure. The city is the current headquarter of Akoko North-East Local Government Area in Ondo State. It is located at an elevation of about 462 meters above sea level. Its coordinates are $7^{\circ} 31^{\prime}$ North and $5^{\circ} 45^{\prime}$ East. It covers an estimated area of about $30 \mathrm{~km}^{2}$. The topography is that of a hilly environment, gently undulating. Ikare Akoko falls within the rainforest zone where leaves are ever green during the rainy season and capable of shedding leaves during the dry season. Ikare Akoko is a chief commercial city in Ondo State with several industrial base and markets. The research was carried out around Oja Oba market and other markets which have several shop outlets for building materials that are sold to customers from within and around the city.

The two cities lie within the migmatite gneiss-quartzite complex of Southwestern Nigeria, generally referred to as the undifferentiated gneiss migmatite complex $[17,18]$. The major types of rocks found in the area are the granite gneiss, migmatite, and Charnokite. Igneous rock such as granite had been identified to contain high levels of radionuclides [3].

\section{Measurement Procedure}

The detector used for this research was a high performance well calibrated Sodium Iodide handheld Inspector 1000 spectrometer, Figure 3. The instrument is specially designed for environmental screening and field measurements application requiring dose and count rate measurement. It has an energy range of $50 \mathrm{KeV}$ to $3 \mathrm{MeV}$. The dose measured correspond to the equivalent dose on the depth of the human tissue $(H * 10)$. The gamma dose rate measurements were performed by placing the detector at a height of one meter above the ground surface with the probe facing downward. Three consecutive readings were taken in a location for six minutes each [12] and the average recorded to represent the value for the particular location. The instrument was carried from one building material store to 
another and the procedure was repeated in each case. The indoor measurements were performed inside the shops and warehouse where the materials are kept while the outdoor measurements were taken where the materials are displayed outside the stores. The background radiation were measured on the roads and distanced from where the building materials are displayed. The distance of each warehouse from the road varied from location to location. It ranged from a distance of $3 \mathrm{~m}$ to about 10 $\mathrm{m}$.

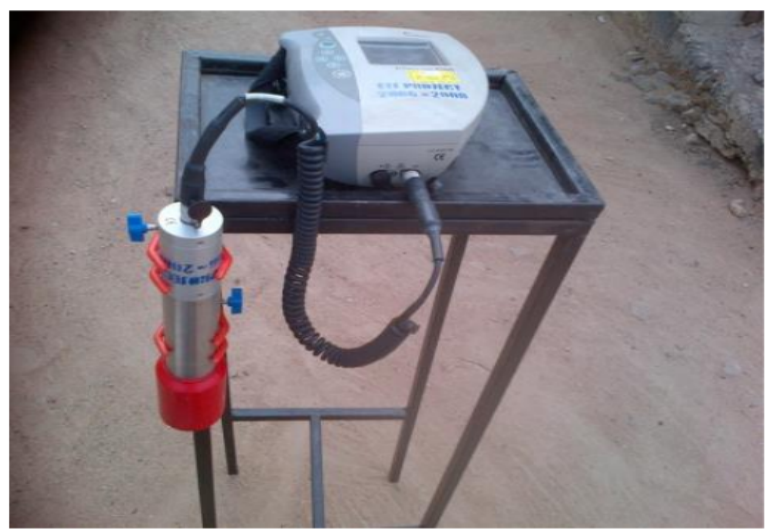

Figure 1. Inspector 1000 spectrometer

The total number of shops covered in this research were 32 shops in Ikare Akoko and 55 shops in Akure city. The type of building materials in the two cities and the number of shops selling a particular building materials are shown in the Table of values. A total of 19 different building materials types were found in the markets.

\section{Results and Discussions}

\subsection{Gamma Dose Rate}

The gamma dose rate values are direct measurements value from the instrument. Tables 1 and 2 present the results of both indoor and outdoor gamma exposure dose rate levels in Ikare Akoko and Akure city. The tables present the range of values, the mean gamma dose values and background dose rate levels for each type of building material at various stores.

The background dose measured on the roads and distance from where the building materials were being sold showed the environmental dose in the local typical environment outside the building of the shop/store. In Ikare Akoko, the gamma dose rate background values ranges from $(0.045 \pm 0.01$ to $0.065 \pm 0.01)$ $\mu \mathrm{Svh}^{-1}$ with a mean value of $0.052 \mu \mathrm{Svh}^{-1}$. In Akure, the background gamma dose rate value ranges from $(0.048 \pm 0.01$ to $0.063 \pm 0.01) \mu \mathrm{Svh}^{-1}$ with a mean value of $0.059 \mu \mathrm{Svh}^{-1}$.

In Ikare Akoko city, for the building materials kept inside the stores, the indoor gamma dose rate ranges from (0.08 to $0.140) \mu \mathrm{Svh}^{-1}$ with a range of mean value from $(0.093 \pm 0.01$ to $0.128 \pm 0.01) \mu \mathrm{Svh}^{-1}$ while for the materials displayed outside, the outdoor gamma dose rate ranges from (0.05 to 0.010) $\mu \mathrm{Svh}^{-1}$ with a range of mean value between $(0.065 \pm 0.01$ to $0.094 \pm 0.01) \mu \mathrm{Svh}^{-1}$. The mean dose rate value from all the building materials available in the stores was $0.104 \pm 0.01 \mu \mathrm{Svh}^{-1}$ for materials kept indoor and $0.079 \pm 0.01 \mu \mathrm{Svh}^{-1}$ for materials displayed outdoor. In Akure city, for the building materials kept inside the stores, the indoor gamma dose rate ranges from (0.08 to 0.110$) \mu \mathrm{Svh}^{-1}$ with a ranges of mean value between $(0.076 \pm 0.01$ to $0.115 \pm 0.01) \mu \mathrm{Svh}^{-1}$ while for the materials displayed outside, the outdoor gamma dose rate ranges from (0.05 to 0.09$) \mu \mathrm{Svh}^{-1}$ with a range of mean value between $(0.062 \pm 0.01$ to $0.093 \pm 0.01) \mu \mathrm{Svh}^{-1}$. The mean dose rate value from all the building materials available in the stores was $0.099 \pm 0.01 \mu \mathrm{Svh}^{-1}$ for materials kept indoor and $0.077 \pm 0.01$ $\mu \mathrm{Svh}^{-1}$ for materials displayed outdoor.

\subsection{Annual Effective Dose}

The estimation of exposure scenario for the sales men/women using the shop outlets was based on total exposure from all the building materials listed. This was because there was no shop or warehouse where a single material was being sold; they sell all or more than half of the building materials listed. The mean absorbed dose rate values for each building material indoor and outdoor were used to calculate the annual effective dose. Assuming that exposure was uniformly distributed throughout the year, the occupancy time of $3444 h y^{-1}$ was used based on working for a maximum of 12 hours daily for 6 days in a week and 52 weeks in a year. The occupancy factor of 0.8 for indoor and 0.2 for outdoor was also used.

$$
\mathrm{He}=\mathrm{DTF}
$$

where He is the annual effective dose $\left(m S v y^{-1}\right), D$ is the mean dose rate value $\left(\mu \mathrm{Svh}^{-1}\right), T$ is the time of the year $\left(h y^{-1}\right.$ ) and $F$ is the occupancy factor. Table 3 present the values of annual effective dose in Ikare Akoko and Akure respectively.

The estimated value of annual effective dose due to background dose mean value that could be received outside in a local typical environment in the two cities where measurements were

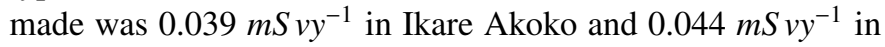
Akure. For Ikare Akoko, the estimated value of annual effective dose from the building materials stores varies from $(0.29$ to 0.383) $m S v y^{-1}$ indoor with a mean value of $0.312 \mathrm{mSvy}^{-1}$ and from (0.049 to 0.070) $m S v y^{-1}$ outdoor with a mean value of $0.059 \mathrm{mSvy}^{-1}$. The total mean annual effective dose value for the occupants of these shops who rotate their sitting position from inside to outside and vice versa for daily typical routine throughout the year was estimated to be $0.371 \mathrm{mS} v y^{-1}$.

For Akure, the estimated value of annual effective dose from the building materials stores varies from (0.230 to 0.357$) m S v y^{-1}$ indoor with a mean value of $0.298 \mathrm{mS} \mathrm{vy}^{-1}$ and from $(0.045$ to 0.069) $m S v y^{-1}$ outdoor with a mean value of $0.057 m S v y^{-1}$. The total mean annual effective dose value for the shop keepers who either stayed outside or inside to attend to customers for a 
typical daily routine business activity throughout the year was estimated to be $0.355 \mathrm{mSvy^{-1 }}$.

In the two cities, the annual effective dose due to exposure from the building materials, was about $12 \%$ higher than the natural background annual effective dose.

\subsection{Excess Gamma Dose}

In both cities the background dose values were less than the outdoor dose rate values and both were less than the indoor dose rate values. If the dose criteria used for control of radioactivity of building materials should be defined as the excess exposure caused by building materials; that is, the background gamma dose from natural radionuclides in the local typical environment need to be subtracted from the gamma dose from building materials [15]. The excess annual effective dose was obtained by subtracting the background annual effective dose obtained in the typical local environment from the total annual effective dose obtained from the total indoor and outdoor exposure from the commercial building materials distribution outlets as shown in Table 4. It could be deduced that the excess gamma radiation dose originating from these building materials increased the annual effective dose received by the sales men or store keepers from either by staying indoors or outdoors with the building materials by $0.332 m S v y^{-1}$ in Ikare Akoko and $0.311 m S v y^{-1}$ in Akure.

When gamma dose are limited to levels below $1 m S v y^{-1}$, controls could be based on a lower dose criteria in the range $0.3-1.0 \mathrm{mSvy} y^{-1}$, if it is judged that this is desirable and will not lead to impractical control [15]. In this research, the excess exposure caused by these building materials were 0.311 and $0.332 \mathrm{mSvy}^{-1}$, which are in the range $0.3-1.0 \mathrm{mSvy}^{-1}$. Therefore, for low dose criteria for control of radioactivity of building materials, control could be based in the range $0.3-1.0$ $m S v y^{-1}$.

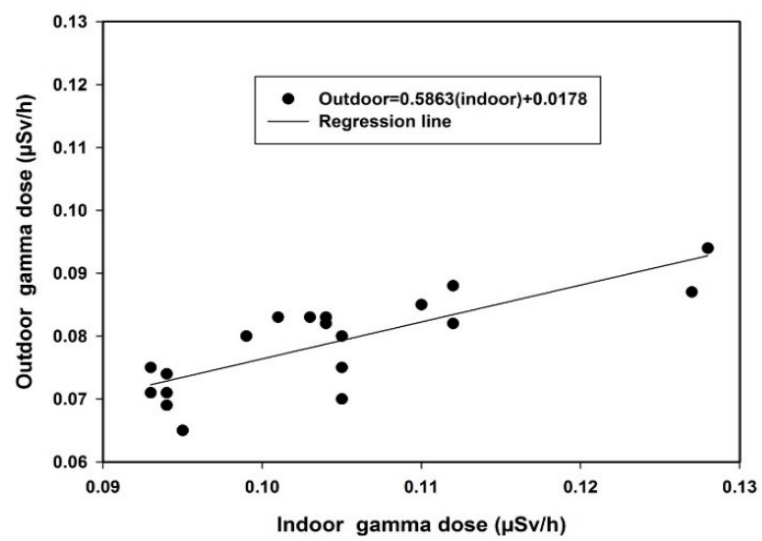

Figure 2. Regression function showing the relationship between indoor and outdoor gamma dose for Ikare city

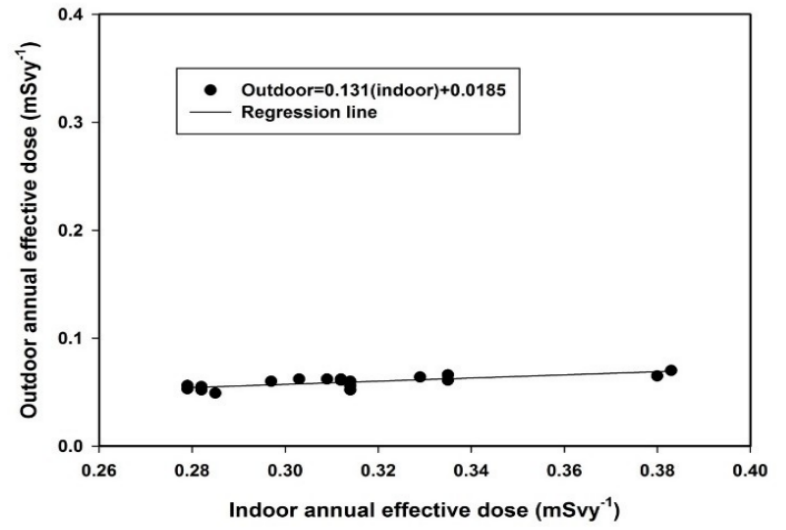

Figure 3. Regression function showing the relationship between indoor and outdoor annual effective dose for Ikare city

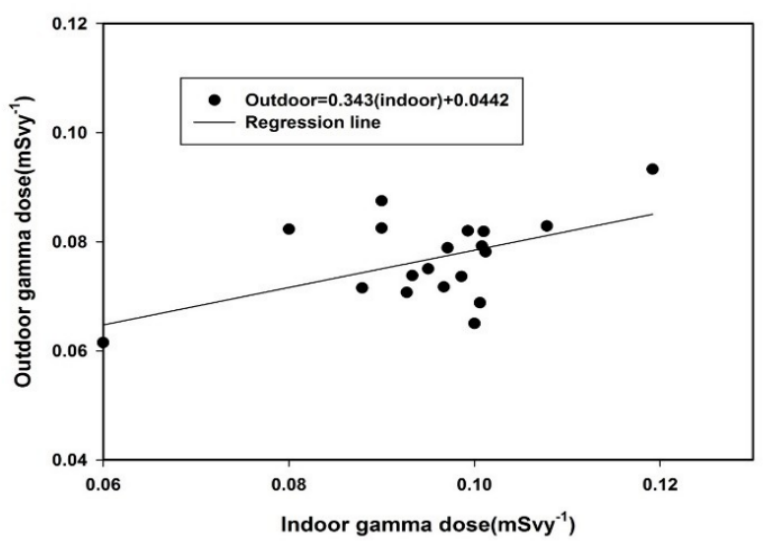

Figure 4. Regression function showing the relationship between indoor and outdoor gamma dose for Akure city

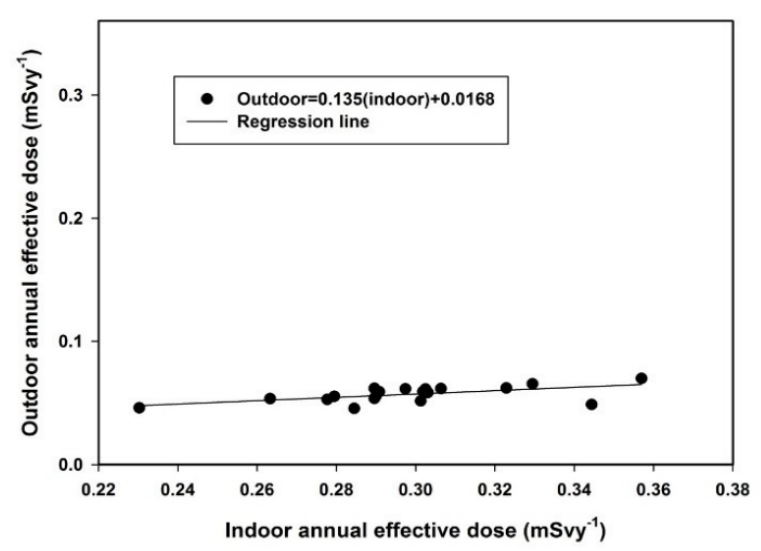

Figure 5. Regression function showing the relationship between indoor and outdoor annual effective dose for Akure city

\subsection{Correlation cross-plot between indoor and outdoor radia- tion}

Figure 4.3 presents the correlation cross-plot between indoor and outdoor gamma dose for Ikare city while Figure 4.3 
Table 1. The range, mean value of indoor and outdoor gamma dose rate and background dose rate level in Ikare Akoko

\begin{tabular}{|c|c|c|c|c|c|c|c|}
\hline$\overline{\mathrm{S} / \mathrm{N}}$ & Building Materials & $\begin{array}{l}\text { No of } \\
\text { shops }\end{array}$ & $\begin{array}{l}\text { Indoor dose } \\
(\mu \mathrm{Sv} / \mathrm{h})\end{array}$ & & $\begin{array}{l}\text { outdoor dose } \\
(\mu \mathrm{Sv} / \mathrm{h})\end{array}$ & & $\begin{array}{l}\text { Background dose } \\
(\mu \mathrm{Sv} / \mathrm{h})\end{array}$ \\
\hline & & & Range & Mean \pm SD & Range & Mean \pm SD & \\
\hline 1 & Corrugated & 7 & $\begin{array}{l}0.080 \\
0.120\end{array}$ & $0.104 \pm 0.01$ & $0.070-.110$ & $0.083 \pm .01$ & $0.061 \pm 0.01$ \\
\hline 2 & $\begin{array}{l}\text { Aluminum Roofing } \\
\text { Sheets }\end{array}$ & 7 & $0.080-0.120$ & $0.105 \pm 0.01$ & $0.070-.110$ & $0.070 \pm 0.03$ & $0.058 \pm 0.01$ \\
\hline 3 & Conduit Pipes & 10 & $0.090-0.120$ & $0.104 \pm 0.01$ & $0.060-.100$ & $0.082 \pm .01$ & $0.054 \pm 0.01$ \\
\hline 4 & Paints & 9 & $0.090-0.130$ & $0.112 \pm 0.01$ & $0.070-.110$ & $0.082 \pm 0.01$ & $0.054 \pm 0.01$ \\
\hline 5 & Cements & 5 & $0.120-0.140$ & $0.128 \pm 0.01$ & $0.080-.100$ & $0.094 \pm .01$ & $0.062 \pm 0.01$ \\
\hline 6 & Pvc Pipes & 11 & $0.090-0.130$ & $0.112 \pm 0.01$ & $0.060-.100$ & $0.088 \pm .01$ & $0.055 \pm 0.01$ \\
\hline 7 & Wash Hand Basin & 6 & $0.080-0.090$ & $0.093 \pm 0.0$ & $0.060-.100$ & $0.075 \pm 0.02$ & $0.04 \pm 0.01$ \\
\hline 8 & Bath Tub & 8 & $0.080-0.110$ & $0.099 \pm 0.01$ & $0.060-.100$ & $0.080 \pm 0.01$ & $0.049 \pm 0.01$ \\
\hline 9 & Water Closet & 7 & $0.080-0.120$ & $0.101 \pm 0.01$ & $0.060-.100$ & $0.083 \pm 0.02$ & $0.050 \pm 0.01$ \\
\hline 10 & Kitchen Zinc & 10 & $0.080-0.130$ & $0.103 \pm 0.01$ & $0.060-.100$ & $0.083 \pm 0.01$ & $0.052 \pm 0.01$ \\
\hline 11 & Asbestos & 7 & $0.080-0.110$ & $0.094 \pm 0.01$ & 0.050-.090 & $0.071 \pm 0.01$ & $0.049 \pm 0.01$ \\
\hline 12 & Floor Tiles & 8 & $0.080-0.120$ & $0.094 \pm 0.01$ & $0.060-.080$ & $0.069 \pm 0.01$ & $0.048 \pm 0.01$ \\
\hline 13 & Wall Tiles & 7 & $0.080-0.110$ & $0.093 \pm 0.01$ & $0.060-.080$ & $0.071 \pm 0.01$ & $0.046 \pm 0.01$ \\
\hline 14 & Bullet-Proof Door & 2 & $0.090-0.100$ & $0.095 \pm 0.01$ & 0.060-.070 & $0.065 \pm 0.01$ & $0.045 \pm 0.01$ \\
\hline 15 & $\begin{array}{l}\text { Binding Wire, Rings } \\
\& \text { Rods }\end{array}$ & 3 & $0.110-0.130$ & $0.127 \pm 0.01$ & $0.080-.090$ & $0.087 \pm 0.01$ & $0.053 \pm 0.01$ \\
\hline 16 & Red Bricks & 2 & $0.100-0.120$ & $0.110 \pm 0.01$ & $0.080-.090$ & $0.085 \pm 0.01$ & $0.050 \pm 0.01$ \\
\hline 17 & Galvanized Pipes & 2 & $0.090-0.120$ & $0.105 \pm 0.02$ & 0.070-.090 & $0.080 \pm 0.01$ & $0.050 \pm 0.01$ \\
\hline 18 & Copper Pipes & 2 & $0.090-0.120$ & $0.105 \pm 0.02$ & 0.060-.090 & $0.075 \pm 0.02$ & $0.055 \pm 0.01$ \\
\hline 19 & Water Tanks & 5 & $0.080-0.110$ & $0.094 \pm 0.01$ & $0.060-.090$ & $0.074 \pm 0.01$ & $0.05 \pm 0.01$ \\
\hline
\end{tabular}

Table 2. The range, mean value of indoor and outdoor gamma dose rate and background dose rate level in Akure

\begin{tabular}{|c|c|c|c|c|c|c|c|}
\hline$\overline{\mathrm{S} / \mathrm{N}}$ & Building Materials & $\begin{array}{l}\text { No of } \\
\text { shops }\end{array}$ & $\begin{array}{l}\text { Indoor dose } \\
(\mu \mathrm{Sv} / \mathrm{h})\end{array}$ & & $\begin{array}{l}\text { outdoor dose } \\
(\mu \mathrm{Sv} / \mathrm{h})\end{array}$ & & $\begin{array}{l}\text { Background dose } \\
(\mu \mathrm{Sv} / \mathrm{h})\end{array}$ \\
\hline & & & Range & Mean \pm SD & Range & Mean \pm SD & \\
\hline 1 & $\begin{array}{ll}\text { Iron } & \text { Corrugated } \\
\text { Sheets } & \end{array}$ & 12 & $0.07-0.13$ & $0.0967 \pm 0.02$ & $0.05-0.09$ & $0.0717 \pm 0.01$ & $0.0525 \pm 0.01$ \\
\hline 2 & $\begin{array}{l}\text { Aluminum Roofing } \\
\text { Sheets }\end{array}$ & 14 & $0.08-0.13$ & $0.0986 \pm 0.01$ & $0.05-0.09$ & $0.0736 \pm 0.01$ & $0.0554 \pm 0.01$ \\
\hline 3 & Conduit Pipes & 11 & $0.08-0.13$ & $0.1012 \pm 0.02$ & $0.06-0.11$ & $0.07818 \pm 0.01$ & $0.0618 \pm 0.01$ \\
\hline 4 & Paints & 15 & $0.07-0.13$ & $0.0927 \pm 0.02$ & $0.05-0.09$ & $0.0707 \pm 0.01$ & $0.0533 \pm 0.01$ \\
\hline 5 & Cements & 12 & $0.09-0.14$ & $0.1192 \pm 0.02$ & $0.07-0.12$ & $0.0933 \pm 0.01$ & $0.0717 \pm 0.01$ \\
\hline 6 & Pvc Pipes & 21 & $0.07-0.13$ & $0.1010 \pm 0.02$ & $0.05-0.10$ & $0.0819 \pm 0.1$ & $0.0624 \pm 0.01$ \\
\hline 7 & Wash Hand Basin & 9 & $0.08-0.13$ & $0.1078 \pm 0.01$ & 0.06-0.09 & $0.0829 \pm 0.01$ & $0.0633 \pm 0.01$ \\
\hline 8 & Bath Tub & 15 & $0.08-0.13$ & $0.0993 \pm 0.01$ & $0.07-0.09$ & $0.082 \pm 0.01$ & $0.0627 \pm 0.01$ \\
\hline 9 & Water Closet & 13 & $0.08-0.12$ & $0.1008 \pm 0.09$ & $0.06-0.08$ & $0.0792 \pm 0.01$ & $0.0546 \pm 0.01$ \\
\hline 10 & Kitchen Zinc & 17 & $0.08-0.12$ & $0.1006 \pm 0.01$ & $0.05-0.09$ & $0.0688 \pm 0.01$ & $0.0542 \pm 0.01$ \\
\hline 11 & Asbestos & 19 & $0.06-0.13$ & $0.0879 \pm 0.02$ & $0.04-0.09$ & $0.0715 \pm 0.02$ & $0.0563 \pm 0.01$ \\
\hline 12 & Floor Tiles & 27 & $0.07-0.12$ & $0.0933 \pm 0.01$ & $0.06-0.09$ & $0.0738 \pm 0.01$ & $0.0567 \pm 0.01$ \\
\hline 13 & Wall Tiles & 17 & $0.08-0.12$ & $0.0971 \pm 0.01$ & $0.06-0.10$ & $0.0789 \pm 0.01$ & $0.0476 \pm 0.01$ \\
\hline 14 & Bullet-Proof Door & 2 & $0.09-0.10$ & $0.095 \pm 0.01$ & $0.07-0.08$ & $0.075 \pm 0.01$ & $0.0550 \pm 0.01$ \\
\hline 15 & $\begin{array}{l}\text { Binding Wire, Rings } \\
\& \text { Rods }\end{array}$ & 13 & $0.06-0.09$ & $0.06-0.09$ & $0.05-0.07$ & $0.0615 \pm 0.01$ & $0.0492 \pm 0.01$ \\
\hline 16 & Red Bricks & 4 & $0.10-0.13$ & $0.10-0.13$ & $0.05-0.08$ & $0.065 \pm 0.01$ & $0.0475 \pm 0.01$ \\
\hline 17 & Galvanized Pipes & 4 & $0.09-0.13$ & $0.09-0.13$ & $0.07-0.11$ & $0.0875 \pm 0.01$ & $0.055 \pm 0.01$ \\
\hline 18 & Copper Pipes & 4 & $0.09-0.13$ & $0.09-0.13$ & $0.06-0.11$ & $0.0825 \pm 0.02$ & $0.050 \pm 0.01$ \\
\hline 19 & Water Tanks & 13 & $0.08-0.13$ & $0.08-0.13$ & $0.06-0.11$ & $0.0823 \pm 0.01$ & $0.0538 \pm 0.01$ \\
\hline
\end{tabular}


Table 3. Indoor and Outdoor Annual Effective Dose in Ikare Akoko and Akure Respectively

\begin{tabular}{|c|c|c|c|c|c|}
\hline $\mathrm{S} / \mathrm{N}$ & Building Materials & $\begin{array}{l}\text { Ikare Akoko } \\
\text { Indoor Dose } \\
(\mathrm{mSv} / \mathrm{y})\end{array}$ & $\begin{array}{l}\text { Outdoor Dose } \\
(\mathrm{mSv} / \mathrm{y})\end{array}$ & $\begin{array}{l}\text { Akure } \\
\text { Indoor Dose } \\
(\mathrm{mSv} / \mathrm{hy})\end{array}$ & $\begin{array}{l}\text { Outdoor } \\
\text { Dose } \\
(\mathrm{mSv} / \mathrm{y})\end{array}$ \\
\hline 1 & $\begin{array}{l}\text { Corrugated } \\
\text { Sheets }\end{array}$ & $0.312 \pm 0.01$ & $0.062 \pm 0.01$ & $0.2896 \pm 0.02$ & $0.0537 \pm 0.01$ \\
\hline 2 & $\begin{array}{l}\text { Aluminum Roofing } \\
\text { Sheets }\end{array}$ & $0.314 \pm 0.01$ & $0.052 \pm 0.03$ & $0.2899 \pm 0.01$ & $0.0551 \pm 0.01$ \\
\hline 3 & Conduit Pipes & $0.312 \pm 0.01$ & $0.061 \pm 0.01$ & $0.3031 \pm 0.02$ & $0.0585 \pm 0.01$ \\
\hline 4 & Paints & $0.335 \pm 0.01$ & $0.061 \pm 0.01$ & $0.2777 \pm 0.02$ & $0.0529 \pm 0.01$ \\
\hline 5 & Cements & $0.383 \pm 0.01$ & $0.070 \pm 0.01$ & $0.3570 \pm 0.02$ & $0.0699 \pm 0.01$ \\
\hline 6 & Pvc Pipes & $0.335 \pm 0.01$ & $0.066 \pm 0.01$ & $0.3025 \pm 0.02$ & $0.0613 \pm 0.1$ \\
\hline 7 & Wash Hand Basin & $0.279 \pm 0.01$ & $0.056 \pm 0.02$ & $0.3229 \pm 0.01$ & $0.0621 \pm 0.01$ \\
\hline 8 & Bath Tub & $0.297 \pm 0.01$ & $0.060 \pm 0.01$ & $0.2974 \pm 0.01$ & $0.0614 \pm 0.01$ \\
\hline 9 & Water Closet & $0.303 \pm 0.01$ & $0.062 \pm 0.02$ & $0.3019 \pm 0.01$ & $0.0593 \pm 0.01$ \\
\hline 10 & Kitchen Zinc & $0.309 \pm 0.01$ & $0.062 \pm 0.01$ & $0.3013 \pm 0.01$ & $0.0516 \pm 0.01$ \\
\hline 11 & Asbestos & $0.282 \pm 0.01$ & $0.053 \pm 0.01$ & $0.2633 \pm 0.02$ & $0.0535 \pm 0.02$ \\
\hline 12 & Floor Tiles & $0.282 \pm 0.01$ & $0.052 \pm 0.01$ & $0.2795 \pm 0.01$ & $0.0553 \pm 0.01$ \\
\hline 13 & Wall Tiles & $0.279 \pm 0.01$ & $0.053 \pm 0.01$ & $0.2908 \pm 0.01$ & $0.0591 \pm 0.01$ \\
\hline 14 & Bullet-Proof Door & $0.285 \pm 0.01$ & $0.049 \pm 0.01$ & $0.2845 \pm 0.01$ & $0.0456 \pm 0.01$ \\
\hline 15 & $\begin{array}{l}\text { Binding Wire, Rings } \\
\text { \& Rods }\end{array}$ & $0.380 \pm 0.01$ & $0.065 \pm 0.01$ & $0.2303 \pm 0.01$ & $0.0461 \pm 0.01$ \\
\hline 16 & Red Bricks & $0.329 \pm 0.01$ & $0.064 \pm 0.01$ & $0.3444 \pm 0.01$ & $0.0487 \pm 0.01$ \\
\hline 17 & Galvanized Pipes & $0.314 \pm 0.02$ & $0.060 \pm 0.01$ & $0.3295 \pm 0.02$ & $0.0655 \pm 0.01$ \\
\hline 18 & Copper Pipes & $0.314 \pm 0.02$ & $0.056 \pm 0.02$ & $0.2896 \pm 0.02$ & $0.0618 \pm 0.02$ \\
\hline 19 & Water Tanks & $0.282 \pm 0.01$ & $0.055 \pm 0.01$ & $0.3064 \pm 0.01$ & $0.0616 \pm 0.01$ \\
\hline 1 & $\begin{array}{l}\text { Corrugated } \\
\text { Sheets }\end{array}$ & $0.312 \pm 0.01$ & $0.062 \pm 0.01$ & $0.2896 \pm 0.02$ & $0.0537 \pm 0.01$ \\
\hline 2 & $\begin{array}{l}\text { Aluminum Roofing } \\
\text { Sheets }\end{array}$ & $0.314 \pm 0.01$ & $0.052 \pm 0.03$ & $0.2899 \pm 0.01$ & $0.0551 \pm 0.01$ \\
\hline 3 & Conduit Pipes & $0.312 \pm 0.01$ & $0.061 \pm 0.01$ & $0.3031 \pm 0.02$ & $0.0585 \pm 0.01$ \\
\hline 4 & Paints & $0.335 \pm 0.01$ & $0.061 \pm 0.01$ & $0.2777 \pm 0.02$ & $0.0529 \pm 0.01$ \\
\hline 5 & Cements & $0.383 \pm 0.01$ & $0.070 \pm 0.01$ & $0.3570 \pm 0.02$ & $0.0699 \pm 0.01$ \\
\hline 6 & Pvc Pipes & $0.335 \pm 0.01$ & $0.066 \pm 0.01$ & $0.3025 \pm 0.02$ & $0.0613 \pm 0.1$ \\
\hline 7 & Wash Hand Basin & $0.279 \pm 0.01$ & $0.056 \pm 0.02$ & $0.3229 \pm 0.01$ & $0.0621 \pm 0.01$ \\
\hline 8 & Bath Tub & $0.297 \pm 0.01$ & $0.060 \pm 0.01$ & $0.2974 \pm 0.01$ & $0.0614 \pm 0.01$ \\
\hline 9 & Water Closet & $0.303 \pm 0.01$ & $0.062 \pm 0.02$ & $0.3019 \pm 0.01$ & $0.0593 \pm 0.01$ \\
\hline 10 & Kitchen Zinc & $0.309 \pm 0.01$ & $0.062 \pm 0.01$ & $0.3013 \pm 0.01$ & $0.0516 \pm 0.01$ \\
\hline 11 & Asbestos & $0.282 \pm 0.01$ & $0.053 \pm 0.01$ & $0.2633 \pm 0.02$ & $0.0535 \pm 0.02$ \\
\hline 12 & Floor Tiles & $0.282 \pm 0.01$ & $0.052 \pm 0.01$ & $0.2795 \pm 0.01$ & $0.0553 \pm 0.01$ \\
\hline 13 & Wall Tiles & $0.279 \pm 0.01$ & $0.053 \pm 0.01$ & $0.2908 \pm 0.01$ & $0.0591 \pm 0.01$ \\
\hline 14 & Bullet-Proof Door & $0.285 \pm 0.01$ & $0.049 \pm 0.01$ & $0.2845 \pm 0.01$ & $0.0456 \pm 0.01$ \\
\hline 15 & $\begin{array}{l}\text { Binding Wire, Rings } \\
\text { \& Rods }\end{array}$ & $0.380 \pm 0.01$ & $0.065 \pm 0.01$ & $0.2303 \pm 0.01$ & $0.0461 \pm 0.01$ \\
\hline 16 & Red Bricks & $0.329 \pm 0.01$ & $0.064 \pm 0.01$ & $0.3444 \pm 0.01$ & $0.0487 \pm 0.01$ \\
\hline 17 & Galvanized Pipes & $0.314 \pm 0.02$ & $0.060 \pm 0.01$ & $0.3295 \pm 0.02$ & $0.0655 \pm 0.01$ \\
\hline 18 & Copper Pipes & $0.314 \pm 0.02$ & $0.056 \pm 0.02$ & $0.2896 \pm 0.02$ & $0.0618 \pm 0.02$ \\
\hline 19 & Water Tanks & $0.282 \pm 0.01$ & $0.055 \pm 0.01$ & $0.3064 \pm 0.01$ & $0.0616 \pm 0.01$ \\
\hline
\end{tabular}

presents the cross-plot showing annual effective dose for the same city.

The equation inscribed in Figure 4.3 shows the relationship between indoor and outdoor gamma dose for Ikare City.
The equation was obtained from simple linear regression using the experimentally acquired data. The equation is characterized with high degree of precision as measured from its root mean square error as well as the mean absolute error. Similar 
Table 4. Excess Annual Effective Dose (mSvy -1) in Ikare Akoko and Akure Respectively

\begin{tabular}{cccccccccc}
\hline & \multicolumn{3}{c}{ Ikare } & \multicolumn{5}{c}{ Akure } \\
\hline Outdoor & Indoor & Total & Background & Excess & Outdoor & Indoor & Total & Background & Excess \\
\hline 0.059 & 0.312 & 0.371 & 0.039 & 0.331 & 0.057 & 0.298 & 0.355 & 0.044 & 0.311 \\
\hline
\end{tabular}

equation relating the indoor and outdoor effective annual dose for the same Ikare city is presented in Figure 4.3. Figure 4.3 and Figure 4.3 respectively presents the correlation cross-plot between indoor/outdoor gamma dose and annual effective dose for Akure City.

Implementation of equations would definitely enhance quick determination of outdoor gamma dose and annual effective dose for every known indoor radiation.

\section{Recommendations}

In order to limit the level of exposure, shop/storekeepers should stay outside their shops more than they stay inside because the indoor radiation dose is more than the outdoor radiation dose. In the two cities, the indoor exposure to gamma dose was $84 \%$ of the total dose. The gamma exposure could be reduced by improving the ventilation in their stores, and it is advisable for them to spend less time, say about 10 hours or less a day for 6 days in a week for 50 weeks in a year, in order to reduce their level of exposure. However, because of confined space and very poor ventilation inside these shops/stores, these sales men may be subjected to high internal exposure by inhalation of radon and its short-lived progeny. Exposure to low doses of gamma radiation in these shops may not cause immediate health effect but it is a minor contributor to overall cancer risk because the risk increases as the dose increases. It is therefore advisable for Nigerians that are involved in this kind of business to put good ventilation of their stores into consideration. The practice of having one small window or no window at all in these shops increases their level of internal exposure to high radon gas inhalation.

\section{Conclusions}

The gamma dose rate exposure levels in typical commercial building materials distribution outlets in Ikare Akoko and Akure, Ondo State, Nigeria, has been carried out. The results showed that the total average annual effective dose received by the store keepers from both indoor and outdoor exposure to radionuclides emission from building materials were 0.371 $\mathrm{mSv} / \mathrm{y}$ and $0.355 \mathrm{mSv} / \mathrm{y}$ respectively which is below the international accepted limit of $1 \mathrm{mSv} / \mathrm{y}$ for the general public. The excess gamma radiation dose originating from these building materials increased the background annual effective dose with a value a little above $0.3 \mathrm{mSv} / \mathrm{y}$ in both cities.

\section{References}

[1] A. Chandrasekaran, R. Ravisankar, A. Rajalakshmi, P. Eswaran, P. Vijayagopal \& B. Venkatraman, "Assessment of natural radioactivity and function of minerals in soils of Yelagiri hills, Tamilnadu, India by Gamma Ray spectroscopic and Fourier Transform Infrared (FTIR) techniques with statistical approach" Spectrochimica Acta Part A: Molec. Biomole. Spectro. 136 (2015) 1734, https://dx.doi.org/10.1016/j.saa.2014.10.075.

[2] G. La Verde, A. Raulo, V. D'Avino, V. Roca \& M. Pugliese "Radioactivity content in natural stones used as building materials in Puglia region analysed by high resolution gamma-ray spectroscopy: Preliminary results" Construct. Build. Mate. 239 (2020) 117668, https://doi.org/10.1016/j.conbuildmat.2019.117668.

[3] W. Feng, Y. Zhang, Y. Li, P. Wang, C. Zhu, L. Shi, X. Hou \& X. Qie, "Spatial distribution, risk assessment and influence factors of terrestrial gamma radiation dose in China" J. Environ. Radio. 222 (2020) 106325, https://doi.org/10.1016/j.jenvrad.2020.106325.

[4] E. Hazou \& T. E. Patchali, "Assessment of radiological hazards in the phosphate mining area of Kpogame, Togo", Case Studies in Chem. Environ. Engin. 3 (2021) 100077, https://doi.org/10.1016/j.cscee.2020.100077.

[5] R .M. Anjos, A. J. Juri, A. S. Cid, R. Cardoso \& T. Lacerda,"External gamma-ray dose rate and radon concentration in indoor environments covered with Brazilian granites", J. Environ. Radio. 102 (2011) 1055, https://doi:10.1016/j.jenvrad.2011.06.001.

[6] B.M. Moharram, M.N. Suliman, N.F. Zahran, S.E. Shennawy \& A.R. ElSayed, "External exposure doses due to gamma emitting natural radionuclides in some Egyptian building materials" Appl. Rad. Isot. 70 (2012) 241, https://doi:10.1016/j.apradiso.2011.07.013.

[7] E. Devanesan, J. Chandramohan, G. Senthilkumar, N. Harikrishnan, M. S. Gandhi, S. S. Kolekar \& R. Ravisankar "Natural radioactivity concentrations and dose assessment in coastal sediments along the East Coast of Tamilnadu, India with statistical approach" Acta Ecologica Sinica. 40 (2020) 353, https://doi.org/10.1016/j.chnaes.2019.06.001.

[8] UNSCEAR, "Sources and effects of ionizing radiation without scientific annexes", New York, (2000).

[9] K. A. Pradeep Kumar, G.A. Shanmugha Sundaram, B. K. Sharma, S. Venkatesh \& R. Thiruvengadathan, "Advances in gamma radiation detection systems for emergency radiation monitoring" Nucl. Engin. Tech. 52 (2020) 2151, https://doi.org/10.1016/j.net.2020.03.014.

[10] M. F. Attallaha, H. M. Abdelbarya, E. A. Elsofanya, Y. T. Mohameda \& M. M. Abo-Alyb, "Radiation safety and environmental impact assessment of sludge TENORM waste produced from petroleum industry in Egypt", Process Safety and Environ. Protec. 142 (2020) 308, https://doi.org/10.1016/j.psep.2020.06.012

[11] A. Gelana, A. Mohammed, B. Haftu, T. Endale \& N. Biniyam, "Radiation levels in buildings on the main campus of Haramaya University and at the towns of Harar and Dire Dawa, Eastern Ethiopia” East Afri. J. Sci. 10 (2016) 133.

[12] Wikipeadia, "Background Radiation" http://en.m.wikipedia .org. (2018).

[13] A. M. Asere \& S. O. Sedara, "Determination of Natural Radioactivity Concentration and Radiogenic Heat Production in Selected Quarry Sites in Ondo State, Nigeria" NIPES J. Sci. Tech. Res. 2 (2020) 256, https://doi.org/10.37933/nipes/2.3.2020.6

[14] D. I. Jwanbot, M. M. Izam, G. G. Iyam \& I. S. Agada, "Evaluation of indoor background ionizing radiation profile in some hospitals in Jos, Plateau State, Nigeria" J. Nat. Sci. Res. 2 (2012) 7.

[15] N. N. Jibiri \& S.T.U. Obarhua, "Indoor and outdoor gamma dose rate exposure levels in major commercial building materials distribution outlets and their radiological implications to occupants in Ibadan” J. Nat. Sci. Res.. 3 (2013) 25.

[16] S. O. Sedara \& A. M. Asere, "Review of variability of radiogenic heat properties of some rock types as a basis for geothermal characterization in Nigeria" Integrity Res. J. 5 (2020) 82, https://doi.org/10.31248/GJEES20203

[17] A. O. Jayeola, A. C. Ogunleye \& J. Dogo, "An investigation on the water chemistry from geologic controls on water sources around Ikare Akoko 
Area, Southwestyern Nigeria" Inter. J. Sci. Tech. 2 (2014) 140.

Nigeria”. Elizabeth Publishing Co. Lagos. (1976) 41.

[18] M. A. Rahaman, "Review of the Basement Geology of Southwestern 